\title{
Human Rights Anchored in Business: Practice and Challenges in the Palm Oil Sector in Malaysia
}

\author{
ANDIKA AB. WAHAB*
}

The United Nations Guiding Principles on Business and Human Rights aims to address gaps in human rights governance by setting a standard and corporate culture of respecting human rights. In Malaysia, despite growing requirements for sustainable production, the palm oil sector has been implicated in various corporate human rights violations. This article discusses how do three public listed companies in the palm oil sector in Malaysia perform their obligation to respect human rights? This article argues that while large palm oil companies have shown modest progress in realizing their human rights obligation - the lack of regulatory framework, resources, direct market pressure and membership to sustainability standards continue to serve as critical challenges in compensating the gaps in human rights governance.

Keywords: Palm Oil; Due Diligence; Human Rights; Compliance; Certification

*Fellow, Institute of Malaysian \& International Studies, The National University of Malaysia, Malaysia; E-mail: andikawahab@ukm.edu.my

DOI: 10.16934/isr.20.1.201906.1 


\section{INTRODUCTION}

Globalization has brought with it increasing economic interdependence through a rapid expansion of cross-border movement of goods, services, technologies and human capital across the globe. Arguably, such expansion has strengthened trade-related standards as the economic actors compete to provide the best products and services in their respective businesses. While it has benefited the international community on various aspects of life, the globalization and expansion of transnational economic activities have its dark side.

Corporate-related human rights violation has been argued to be one of the critical negative consequences brought by globalization in the context of today's international business. To be more precise, globalization is argued to have created critical gaps in human rights governance. Ruggie $(2008,189)$ highlighted that " $\ldots$ the root cause of the business and human rights predicament today lies in the governance gaps created by globalization - between the scope and impact of economic forces and actors, and the capacity of societies to manage their adverse consequences." The gaps in governance, hence, provide a permissive environment for wrongful acts by unscrupulous companies without adequate reparation.

In 2011, the United Nations' Human Rights Council (UNHRC) endorsed the United Nations Guiding Principles on Business and Human Rights (UNGPBHR) - a global framework that aspires to serve as an authoritative focal point to enhance standards and practices with regard to business and human rights so as to achieve socially sustainable globalization. The UNGP-BHR is grounded in recognition of its core general principles, namely (i) States' existing obligations to respect, protect and fulfil human rights and fundamental freedoms; (ii) the role of business enterprises as specialized organs of society performing specialized functions, required to comply with all applicable laws and to respect human rights; and (iii) the need for rights and obligations to be matched to appropriate and effective remedies when breached (UNHRC 2011, 1).

Human rights in business are no less important in Malaysia. However, most Malaysian-based companies, in all sectors of the economy are not exposed to, or unaware of their corporate human rights responsibility. The Human Rights Commission of Malaysia (SUHAKAM 2015, 1) reported that many Malaysian companies are only familiar with the concept of corporate social responsibility (CSR), but unaware of their human rights responsibility.

In the palm oil sector specifically, there is a pool of certification standards that have components in relation to respecting human rights. Ironically, despite growing certification requirements to respect human rights, palm oil companies in Malaysia have continuously been implicated in violations of human rights ranging from forced labour, debt bondage and child labour cases. For instance, the U.S. Department of State $(2016,255)$ alleged that child labour and forced 
labour are prevalent in palm oil and electronic sectors in Malaysia, citing that one in three migrant workers are in forced labour conditions. Additionally, a growing number of media exposures that have documented serious labour exploitations against migrant workers in the palm oil sector in Malaysia. For example, the Wall Street Journal (2015) had reported labour exploitations committed by a large oil palm company against migrant workers in the plantation sector. These include cases of passports retention, restriction on freedom of association and debt bondage. This article aims to understand and discuss how do companies in the palm oil sector in Malaysia perform their obligation to respect human rights?

\section{WHY PALM OIL IN MALAYSIA? AND WHY NOW?}

Malaysia is uniquely positioned as a Southeast Asia's business hub, attracting more than 5,000 foreign corporations from 40 countries operating their businesses in many key economic sectors including agriculture (Yusof 2017, 1). In this article, I focus on three public listed Malaysian-based palm oil companies. They are Felda Global Ventures (hereinafter referred to as FGV), Sime Darby Plantation (hereinafter referred to as Sime Darby), and Wilmar International (hereinafter referred to as Wilmar). Collectively, these three companies are members of the global sustainable certification standard namely the Roundtable Sustainable Palm Oil (RSPO) which guarantees them in compliance to internationally-recognized human rights standards.

At company level, FGV is the world's largest producer of palm oil with a total of 440,577 hectares of land bank and a total of 70 palm oil mills operated across Malaysia. Sime Darby is a Malaysian-based conglomerate, and a founding member of the RSPO - with a total of 71 palm oil mills, 254 estates and about 102,551 employees across 18 countries around the world. Unlike FGV and Sime Darby, Wilmar is a wide-ranging agribusiness conglomerate in palm-oil related businesses include oil palm cultivation, oilseed crushing, edible oil refining, oleo-chemicals, bio-diesel and fertilizers.

The reasons for choosing palm oil business sector in this article are manifold. First, the palm oil industry is an important source of economic growth and development (Szulczyk 2013, 2), contributing to Malaysia's annual export revenue between RM60 billion (approximately US\$15 billion) and RM70 billion (US\$ 17.5 billion) (Azman 2013, 15). Moreover, Malaysia is the second largest producer of palm oil and a global major exporter.

Secondly, after more than a hundred years of its existence, palm oil is still a labour-intensive sector, hiring a half million of workers - the majority of which are foreign labourers (Azman 2013, 22). Undeniably, the growing demand and expansion of business operations have benefited many pockets including the 
small farmers, local community and workers. However, as the palm oil business proliferates, so has the alleged human rights harms in the palm oil sector. On this note, it is worth mentioning that for the past few years, an increasing number of watchdogs' reports have documented serious labour exploitation against foreign workers in the palm oil sector in Malaysia. These include a report published by Finnwatch (2014) which monitors the realization of labour rights in the activities of Finnish companies and their supply chains, including some Malaysian palm oil companies. This justifies another reason why palm oil business is the focus of this article.

In Malaysia, business conducts are governed by the existing national laws and regulations, which include the prohibition of forced and child labour, respecting customary land and indigenous people rights, compliance to safety and health, implementation of minimum wage, restriction of excessive working hours, and the enjoyment of the right to association. However, human rights in the business sector in Malaysia focuses much on complying with the right to safety and health, and barely pays attention to other labour and human rights as mentioned above.

Businesses in Malaysia are very much accustomed to the concept of CSR (SUHAKAM 2015, 1) - a set of voluntary actions companies undertake that goes beyond compliance with the existing laws and regulation. In fact, Malaysia is deemed to be one of the emerging economies that is involved in CSR activity (Thompson and Zakaria 2004, 135). As part of their CSR activity, many businesses especially Malaysian public listed companies are engaged in corporate disclosure and publicly reporting their social responsibility activities (Mohd Nasir et al. 2013, 84).

In 2007, the Securities Commission (SC) and Bursa Malaysia began to impose a mandatory requirement for all public listed companies to report their CSR activities (Human Rights Resource Centre 2013, 223). In addition, the Securities Commission promulgated the Malaysian Code for Corporate Governance and the Bursa Corporate Governance Guide - which encourage corporate directors to consider producing sustainability reports that address a company's community involvement activities, provision of equal opportunity and diversity, prohibition of child labour, access to grievance and freedom of association (Human Rights Resource Centre 2013, 223-224). Furthermore in 2014, the government of Malaysia through its regulatory body, Bursa Malaysia, initiated the FTSE4Good Bursa Malaysia Index, which requires companies who wish to be included in the index to achieve the set requirements such as monitoring and reporting companies' commitment on human and labour rights, supply chain labour standards, climate change and countering briber (Nordin et al. 2016, 106-107).

Despite the presence of sustainability certification standards such as the RSPO, the industry's enforcement of human rights standards is weak and 
insufficient to address human rights harms in the palm oil sector (Varkkey 2015, 155). Human rights campaigning NGOs such as Amnesty International and Rainforest Action Network (RAN) have criticized the RSPO for having a little concern for the welfare of palm oil workers, and strongly citing that it is a not reliable certification scheme that could ensure sustainable and responsible palm oil production (Chow and Ananthalakshmi 2016, 1).

In view of the mounting pressure on corporate-related human rights harms, and a relatively slower progress from the government of Malaysia in relation to having a strong governance structure on business and human rights SUHAKAM published its Strategic Framework on National Action Plan (NAP) on Business and Human Rights in 2015. The strategic framework aims to support the government to develop a dedicated NAP to guide businesses to respect human rights. However, as of end 2018, the government has yet to adopt such NAP, leaving corporations in Malaysia unregulated of their human rights obligations.

\section{RESEARCH APPROACH AND DESIGN}

Leading scholars in the field of social sciences argue that knowledge and reality are socially constructed, and that makes it almost impossible for researchers to explain it objectively (Creswell 2009, 7-8; Thanh and Thanh 2015, $25)$. Some issues or phenomenon in our society require an act of describing and explaining it in the right context, beyond merely a rigid analytical framework and numerical approach. As such, this article employs a descriptive inference approach. King, Keohane and Verba $(1994,7-8)$ argue that one part of the descriptive inference approach requires researchers to infer information about unobserved facts from the facts we have observed. Such observation must be systematic and conducted with appropriate research procedures. For instance, researchers must be able to describe and connect causes and effects, and explain such relationship coherently.

This article is qualitative in nature, intending to describe and explain how companies in the palm oil sector respect and practice human rights in their respective business operations. This article relies heavily on publicly available sources comprising companies' annual and sustainability reports, sustainability progress updates, sustainability dashboards and other related sustainability information available in their respective official websites. Triangulation of information especially from non-business and third-party organizations including media outlets and NGOs are of paramount importance to provide alternative views of practices and progress made by these companies. For that purpose, this article makes reference to several reports and exposures relevant to issues raised in this article. 
The UNGP-BHR, specifically the Second Pillar of the authoritative document, namely the Corporate Responsibility to Respect Human Rights - serves as the main source of non-rigid discussion framework applied in this article. In discussing how the selected Malaysian palm oil companies perform their human rights responsibility, I refer to two operational principles as outlined under the Second Pillar the UNGP-BHR. First is policy commitment, and the second is due diligence. There is another operational principle outlined under the Second Pillar of the UNGP-BHR namely, remediation. However, to discuss what has been done by businesses in remediation requires detailed information - more often sensitive data from these companies. As such, I do not include the operational principle of remediation in this article.

Under policy commitment, there are three components discussed. First, is policy comprehensiveness under which this article aims to explore whether the existing company's policy or statement is on par and/or aligned with the international human rights standards, including the Universal Declaration of Human Rights (UDHR, 1948) and other instruments through which it has been codified, as well as International Labour Organization's (ILO) core conventions. Second, is policy development and socialization. This component discusses several aspects such as the adoption of policies by the highest authorities of the company, policy development process, internal and external socialization, and conversion of policy into internal procedures and mechanisms. Third, is policy coverage that seeks to discuss the extent of their human rights commitment covering their respective supply chains.

Under due diligence, this article discusses three components. First, is governance and strategy. The UNGP-BHR does specify the need for companies to have an appropriate due diligence process in place - with a clear objective to identify, prevent and mitigate human rights impacts (UNHRC 2011, 16). To carry out this ambitious commitment, companies require a strong governance structure in steering leadership and decision-making, setting up priorities and developing a roadmap. These aspects coupled with companies' strategy in conducting due diligence are discussed. Second, is expertise and collaboration, which aim to discover the involvement of external and independent human rights experts (individual or organization) to assist companies in carrying out due diligence. Third, is monitoring, aiming to understand monitoring efforts undertaken by these companies to track the effectiveness of their human rights initiatives, including the implementation of findings deriving from their due diligence exercise. 


\section{EMBRACING HUMAN RIGHTS INTO PALM OIL BUSINESS' PRACTICES}

\section{Policy commitment}

\section{1) Policy comprehensiveness}

The policy statement is a form of expression that a company should declare to inform their responsibility and expectation to respect human rights. The UNGP-BHR provides that the term "statement" is used generically to describe whatever means a company employs to publicly set out its responsibility and commitment (UNHRC 2011, 16-17). Based on the understanding that business can have an impact on the entire spectrum of internationally recognized human rights - policy comprehensiveness is an essential element of policy commitment.

The selected companies namely FGV, Sime Darby and Wilmar have expressed their policy commitment to respect human rights as part of their sustainability commitment. Other than human rights, they also make a public commitment to other social and environmental responsibilities. Such commitments are expressed in the different format of the policy statement. FGV, for example, has expressed its human rights policy commitment in its integrated sustainability policy known as FGV's Group Sustainability Policy (GSP). Although FGV does not have a stand-alone human rights policy - the GSP contains a list of human rights commitments that are aligned with the expected international standards. These include: (i) prohibition of forced labour / human trafficking; (ii) decent and fair working conditions; (iii) prohibition of child labour; (iv) equal opportunity and non-discrimination; (v) prohibition on sexual and violence; and (vi) assurance for freedom of expression and the right to form and join union (FGV 2018a).

In addition to the GSP, FGV recently adopted its No Deforestation, No Peat and No Exploitation (NDPE) Policy in 2018, which encloses rather ambitious human rights commitments such as respecting the right of workers to keep their own travel documents (FGV 2018b). It is worth mentioning that the retention of foreign workers' passports and working passes is a legacy issue in the palm oil sector. Companies claimed that by returning foreign workers' documents (e.g., passport) they will face workers absconded from their respective employers (Malaysian Employers Federation 2014, 1-2).

For Sime Darby, its top-level human rights commitment is broadly expressed in its Human Rights Charter, which contains a commitment to ensure equal opportunity to all its workers; guaranteeing their freedom of association; eradicating any forms of labour exploitation; providing decent work; and prohibiting the use child labour, sexual harassment and violence (Sime Darby 
2018a, 4). The charter has clearly articulated its commitment to uphold the highest standards when faced with a conflict between local and international norms. Ensuring that such top-level commitment is delivered to the middle management and operational employees, Sime Darby has further established other management and operational policies concerning human rights. These include its Social and Humanity Management Policy, Social Policy, Gender Policy and Child Protection Policy - all of which support its overarching human rights commitment at the top-level (Sime Darby 2018b).

Sime Darby has not clearly expressed its policy commitment allowing migrant workers to keep their own travel document (unconditionally). The company however reported that it had piloted an exercise of returning foreign workers' passports in its six estates throughout Malaysia (Sime Darby 2017, 3). However, only $10 \%$ of the total 1,200 migrant workers engaged during pilot project stated their preference to keep their own passports. In other words, $90 \%$ of the migrant workers preferred their passports to be kept by management.

Similar to Sime Darby, Wilmar has adopted its stand-alone Human Rights Policy, covering the company's commitment to respect fundamental labour rights such as freedom of association, prohibition of forced, bonded and child labour, and provision of a conducive working environment, and at the same time, upholding indigenous and local community rights. Besides, Wilmar has adopted its NDPE policy, which also reaffirms its overarching human rights commitment stated in its Human Rights Policy. At the operational level, Wilmar (2018a) has established several other human rights-related policies including the Equal Opportunity Policy, Anti-Sexual Harassment, Violence and Abuse and Reproductive Rights Policy, as well as Child Protection Policy. With regard to its commitment to return foreign workers' passports, Wilmar had recently returned passports of its approximately 10,000 migrant workers. To ensure migrant workers will have a secure place to keep their own passports, the company installed easy-to-access lockers (Lee 2018).

\section{2) Policy development and socialization}

The UNGP-BHR stresses that a human rights policy should be approved at the most senior level of companies, and that the level of expertise required to establish a comprehensive policy statement is varied according to the complexity of the companies' operations (UNHRC 2011, 16-17). As members of the RSPO FGV, Sime Darby and Wilmar are required to adopt and implement a policy to respect human rights in their respective business operations and transactions.

Essentially, human rights and other related policies established by FGV, Sime Darby and Wilmar had been approved by the highest level of management. For instance, FGV's GSP was approved and adopted by its Board of Directors. 
FGV has made it clear that the group policy will be reviewed periodically, or at least once in every two years. Similarly, Sime Darby's management policies were approved by its Managing Director, while Wilmar's Human Rights Policy was approved by its Chief Executive Officer. The approval of human rights policies by the highest level of companies' managements depicts a strong pledge from the top management to respect human rights.

Development of human rights policies is an important process, ensuring that the contents referred in such policies are aligned with the expected standards. The UNGP-BHR does not rigidly state that companies must engage expert individual or organizations to help in drafting their human rights policy (UNHRC 2011, 17). Rather, tools and references can be retrieved from readily available online sources to support companies to produce policies that meet the set expectation of business conduct.

FGV announced that it co-signed a memorandum of understanding (MoU) with SUHAKAM in March 2017, subsequently marking its two-year human rights collaboration (Anon 2017). In its sustainability regular update, FGV stated that SUHAKAM had agreed to provide expert views in its related human rights policies and internal procedures in view of further improving its human rights practices throughout its operations (FGV 2018c, 2).

With regard to internal policy socialization - FGV, Sime Darby and Wilmar have clearly indicated their commitment to engage and socialize their human rights policies to all workers, regardless of their position and status of employment (permanent or contract). These commitments are reflected in their respective policy documents, and are expected to be undertaken through a series of awareness-raising activities and training sessions.

Sime Darby's Human Rights Charter states that training for their own workers is important so as to ensure that they truly understand and are well-equipped to influence and encourage their counterparties and business partners to comply with the company's commitment on human rights. As such, the company reported that it had trained more than 870 estate managers, assistant estate managers and heads of township between July 2016 and June 2017 on business and human rights (Sime Darby 2017, 4). Wilmar's Human Rights Policy states that the company will work hand in hand with a broad range of stakeholders in the implementation of its policy (Wilmar 2018a).

FGV, Sime Darby and Wilmar have taken one step further by making their human rights and other related policies available to the public. However, many of these policies are only available in the English language, only a few of them have been translated to other languages especially Bahasa Malaysia (Malaysian language). It is important to note that language is an important medium of communication to ensure suppliers, contractors and society at large are fully apprehended the companies' commitments and responsibilities to respect 
human rights.

Integration of human rights commitment into companies' internal procedures and other operational mechanism is another important step, ensuring that such commitment is fully translated into business practices across different functions and workplaces. As part of its enhanced human rights commitment, FGV informed that it is currently enhancing its internal grievance procedure, providing a safer complaint avenue for its plantation workers to raise labour rights issues (FGV 2018c, 5).

Sime Darby $(2016,22-23)$ reported that it had created a dedicated internal mitigation measure to respond to any human rights violations in its own operations. Some internal departments related to human resource, quality control and compliance management are also expected to conduct their respective human rights assessment from time to time. Besides, the company established a dedicated Plantation Human Rights Task Force in January 2016 with the objective to identify human rights issues exist in its plantation operations for appropriate intervention and resolution (Sime Darby 2016, 23). These initiatives are the actual manifestation of their human rights commitment as outlined in their respective human rights policies.

\section{3) Policy coverage}

Companies may be involved with adverse human rights impacts either through their own activities, or as a result of their business relationship with other parties within its value chain. As such, the UNGP-BHR emphasizes that the responsibility to respect human rights requires companies to prevent and mitigate human rights impacts not only in their own operations, but in their suppliers and business partners' operations, even if they have not virtually contributed to those impacts (UNHRC 2011, 19-20).

Generally, FGV, Sime Darby and Wilmar have clearly indicated the extent to which their policy commitment is extended to their suppliers, business partners and other stakeholders within their respective supply chain. Sime Darby, for instance, extends its human rights commitment to all stakeholders within their own "sphere of influence." The term "sphere of influence" was first used by the United Nations Global Compact (UNGP) in corporate social responsibility discourse that seeks to establish the scope of corporate responsibility on human rights issues (Ruggie 2008, 198-199). The term has also been used widely by multinational corporations to map out their respective value chain, where the word "influence" is referred to as the company's circle of responsibility consists of workers, market place, communities and government.

Following such commitment, Sime Darby $(2017,3)$ reported that it had organized dialogues with its contractors, recruitment service providers and joint 
venture business partners ensuring they adhere to Sime Darby's public commitment to respect human rights. However, it was not made clear whether there was any follow-up action undertaken by the company to track progress and compliance of its business partners.

For Wilmar $(2013,2)$, its NDPE Policy has clearly specified that the policy is applied to its own operations worldwide, and its third-party suppliers from whom they purchase or with whom they have a trade relationship. The company further states that it will cease its business relationship with any suppliers if they commit a serious violation of its NDPE policy. This suggests a strong commitment of Wilmar to ensure that only responsible and human rights-compliance products and services are supplied to its company, despite knowing that by cutting-off trade relationship will have significant implications to their business operation.

\section{Human rights due diligence}

The UNGP-BHR emphasizes that human rights due diligence are important exercise for companies so that they are aware of the risks and the potential remediation they can undertake (UNHRC 2011, 17-19). The processes involved in human rights due diligence should include assessing actual and potential human rights impacts; integrating and acting upon the findings; tracking responses; and communicating how impacts are addressed. The scope of due diligence exercise is context specific - depending on various factors such as the size of the company, severity, nature and their operating context (UNHRC 2011, 21-22). It is also important to note that a clear distinction must be made between conducting human rights due diligence and regular business risk assessment exercise. Risk assessment exercise is primarily aimed at preventing risks to the business itself, or its employees - while human rights due diligence focus on the prevention of impacts on the rights-holder (McCorcuodale et al. 2017, 199-200).

\section{1) Governance and strategy}

Evidently, carrying out human rights due diligence is not a simple undertaking. It can even be more multifaceted when a company has a variety of other business due diligence exercises, involving many of its business operations and suppliers across different countries. This would necessitate a strong leadership and governance structure to strategize, prioritize and execute human rights due diligence.

Human rights issues facing FGV are matters under its sustainabilityrelated division known as the Group Sustainability and Environment Department (GSED). GSED reports directly to the Group President and Board Governance 
Risk Management Committee (FGV 2016, 24). In 2017, FGV came up with a materiality matrix, revealing that human rights are among the top five issues that could potentially impact its business operations. As such, the company identified several mitigation measures aiming primarily to improve its internal procedures and mechanisms ensuring full compliance of its business units. These include strengthening management of migrant workers, and provision of training for its contractors and suppliers.

Due diligence is a regular exercise in FGV. It is one of the key responsibilities of the Certification and Due Diligence (CDD) unit - a sub-department under GSED that is tasked to ensure business compliance against certification requirements such as RSPO and other certification standards (FGV 2016, 24). There is no dedicated due diligence exercise specifically tailored on human rights. However as human rights form some part of the RSPO and other certification standards - aspects of human rights are addressed in the company regular due diligence exercise against these standards.

For Sime Darby, the Sustainability Committee - with the support of the Risk Management Committee and the Governance and Audit Committee are mutually responsible to oversee and address human rights issues. The company's current business due diligence strategy comprises commercial risk and impact assessment across its business operations. Due diligence exercise also involves development and implementation of an action plan, as well as monitoring of its effectiveness.

For Wilmar, the sustainability risk management unit is responsible to strategize and oversee its risk identification initiatives and progress' monitoring. The group risk management structure is currently under the purview of the Board's Risk Management Committee, which reviews issues affecting its sustainability commitment including human rights issues on a quarterly basis. In addition to the existing internal governance structure, Wilmar formed a Joint Steering Committee consists of its owned management team and a not-for-profit organization known as The Forest Trust (TFT) - to handle key sustainability issues and evaluate its progress, in particular the implementation of its NDPE Policy.

Respect for human rights is implemented as part of Wilmar's broader risk management strategy. Other than assessing and tracking the progress of its own business operations, Wilmar endeavours to support its approximately 1,000 supplying mills that span across Malaysia, Indonesia and several countries of operations in Latin America and African regions (Wilmar 2018b). In doing so, the company adopts a transformative strategy known as Aggregator Refinery Transformation (ART) - which includes a strategy to prioritize its supplying mills for field assessment.

ART's field assessment aims to identify issues concerning legal compliance 
and labour rights issues occur in its supplying mills and their respective suppliers, which include estates, small growers and smallholders. As part of its transparency pledge, Wilmar uploaded assessment findings of its suppliers by different regional locations, available in its official sustainability website. With the ART strategy, Wilmar is able to identify a group of its suppliers that require technical assistance and capacity building to address specific issues in their respective locality. Wilmar (2018c) reported that it had organized three broad-level engagement workshops in 2016 (in Malaysia), which were attended by 49 mills and a total of 199 participants.

\section{2) Expertise and collaboration}

The ability to identify potential and actual human rights impacts would require a set of expertise to understand and analyse the root causes and patterns of violations. This includes the ability to determine risk against the companies, as well as the rights-holders. FGV acknowledges the importance of collaboration with human rights experts. Other than signing an MoU with SUHAKAM, FGV has appointed a human rights commissioner from this national institution to be part of its internal high-level committee namely the Social and Human Rights Compliance Steering Committee (The Forest Trust 2017, 126). The commissioner is given the mandate to provide technical and strategic advice to the committee. FGV $(2018 \mathrm{c}, 2)$ reported that SUHAKAM was expected to conduct due diligence visits to its several plantation sites in Sabah and Peninsular Malaysia. However, the outcome of such due diligence visits is yet to be made public.

For Sime Darby, expertise and guidance on human rights have been much leveraged through their strategic collaboration with a not-for-profit organization, known as SHIFT. SHIFT is a not-for-profit organization that was established days after the formal adoption of the UNGP-BHR in 2011. Collaboration with SHIFT is meant to help the company to assess and address human rights issues in its business operations. In 2016, SHIFT had conducted a human right impacts assessment specifically on the hiring of migrant workers, women and children in Sime Darby's own plantations in Malaysia (Sime Darby 2017, 2). Findings of the human rights impact assessment managed to identify potential human rights violations committed by the company, amongst others, the risk to forced labour around the recruitment of its migrant workers. Resulting from the human rights impact assessment undertaken by SHIFT, an assessment methodology was said to be developed to support the integration of human rights principles into its management practices (Sime Darby 2017, 2-3).

Wilmar $(2017,25)$ is the first industry player in the palm oil sector who had adopted NDPE Policy and extended to all its suppliers in the sector. This subsequently calls for a collective action to transform the old tradition in the 
cultivation of oil palm to align with the emerging human rights requirements. In this transformation journey, Wilmar is not alone. Knowing that the journey would require expert support, it made strategic partnerships with several not-for-profit organizations to guide and add value to their transformation journey. As such, the company has been collaborating with TFT, Proforest, Daemeter of the Consortium of Resource Experts (CORE) and AidEnvironment (Wilmar 2017).

Wilmar also announced its collaboration with another labour expert organization known as Verite in order to identify critical labor issues and potential root causes in its own operations in Indonesia (Wilmar and Verite 2017). Through this collaboration, Verite is expected to recommend a set of practical solutions to address labour rights issues, with a clear timeline to be executed by the company. The outcome of this partnership was also expected to be replicated in its operations and supply chains elsewhere including in Malaysia.

\section{3) Effective monitoring}

Monitoring is an important process for companies to know if its human rights policies are executed optimally on the ground, and to drive continuous improvement. Monitoring could be initiated separately, or integrated into a relevant internal reporting system. Monitoring can also be organized as part of companies' regular contract performance review, surveys and audits, as well as by leveraging internal grievance mechanism. The UNGP-BHR stresses that effective monitoring should be based on appropriate quantitative and qualitative data and be able to draw feedback from both internal and external stakeholders (UNHRC 2011, 22).

For FGV, monitoring is part of its due diligence and corrective action undertaken on a regular basis. Following the creation of FGV's Social and Human Rights Action Plan to address labour rights issues in 2016, the company reported that more than half of the action plan had been executed as of March 2018 (FGV $2018 \mathrm{c}, 2)$. These include translation of employment contract in a native language of its migrant workers; provision and sharing of resources such as standard employment contract to its contractors; as well as strong and continuous enforcement on the implementation of minimum wage.

For Sime Darby (2017), monitoring includes continuous assessment and progress tracking of its key suppliers and contractors against the set performance indicators. The company often tracks its suppliers' delivery records, obtain feedback from users and clients, and verify the validity of information supplied to Sime Darby. The company further reported that any critical non-conformance is found among its suppliers and contractors, it will terminate its business relationship. On matters concerning its workers, Sime Darby claimed that its existing Whistleblowing Policy is also used to monitor grievances raised by 
workers (Sime Darby 2017, 21). Grievances can be channelled to the dedicated team where the complainants will be guaranteed with protection (Sime Darby 2017, 95)

For Wilmar, monitoring is part of its broader ART approach. Its monitoring strategy goes beyond identifying issues and monitoring their progress, but providing much needed technical advice and support especially to its suppliers. The company has conducted continuous labour and environmental assessment for its suppliers on a voluntary basis. The outcome of this assessment often results in a customized and time-bound action plan to be remedied by the assessed suppliers. It is then followed by technical assistance and training tallied to the need of its suppliers.

Wilmar (2018c) reported that it has been implementing its Supplier Group Compliance (SGC) verification program since 2013 - with a view to continuously monitor labour and environmental issues at its supplier group level. The SGC process involves an analysis of the company's ownership structure, a compilation of the group's land bank and potential non-compliance with its NDPE Policy. Findings from the SGC are used to help identify issues in real time, and that would enable the company to engage the concerned suppliers. As such, the company is able to resolve many cases before they escalate to become a public grievance. The company is also committed to making this process to be more transparent by updating the outcome of its SGC verification program on a regular basis from September 2018 onwards.

In brief, it is not uncommon for companies to refer to, or integrate human rights principles into their regular business risk assessment or due diligence exercise. This often comes under risk management strategy, and for the purpose to secure their certification compliance against major certification standards such as RSPO. In other circumstance, companies undertake a dedicated human right impacts assessment as a process to identify the root causes and potential remedial actions. Most often such exercise is undertaken in order to respond to the public grievance and/or exposure by campaigning NGOs on any human rights violations linked to the company.

\section{DISCUSSION}

Though FGV, Sime Darby and Wilmar have shown modest progress in performing their human rights obligations, it is limited to their own business operations and a few of their suppliers. Suppliers to FGV, Sime Darby and Wilmar comprise small and medium estates, growers and smallholders which form the majority of the palm oil industry players. FGV alone, for instance, has a total of more than 100,000 smallholders that produce and supply fresh fruit bunches to FGV's mills across the country. Consequently, too few of the palm oil 
industry players that have progressed and reached a scale commensurate with human rights challenges at hand. The next question is - why the responsibility to respect human rights is not equally distributed to all industry players, regardless of their size of operation?

First, I argue that the current legal and regulatory infrastructure in Malaysia does not progress on par with the palm oil business expansion, and their responsibility to respect human rights. Palm oil suppliers are not specifically duty bound to declare their human rights commitment, or to undertake human rights due diligence, and report their progress on a regular basis. However, public listed palm oil companies such as FGV, Sime Darby and Wilmar are required by the corporate regulations to at least report their corporate social responsibility activities which include their human rights obligations. These include their commitment to prohibit child labour, provide assurance for freedom of association and equal opportunity. Nevertheless, such requirements are only imposed to a very small number of businesses as compared to the entire industry players in the palm oil sector. The rest of the companies in particular the small and medium-sized estates, growers and smallholders are left unregulated specific on their human rights commitment.

Secondly, I argue that the lack of resources and capacity hinder suppliers especially small and medium-sized estates, growers and smallholders to perform their human rights obligation. Companies like FGV, Sime Darby and Wilmar have been organizing awareness raising programmes and capacity building initiatives to inspire and equip their suppliers to deliver their human rights obligations. However, the actual implementation of these human rights obligations requires continuous commitment and substantial monetary investment. An easy example such as undertaking a human rights due diligence is a resource-intensive and heavy exercise, requiring sufficient and consistent effort to implement, monitor and evaluate its progress.

Third, is the absence of direct market pressure against suppliers. When campaigning NGOs and regional organizations like the European Commission (EU) lobbying and advocating for the banning of the palm oil products linked to human rights violations - the target often go to large and established companies and brands such as FGV, Sime Darby and Wilmar. The suppliers among small and medium-sized estates, growers and smallholders are barely affected with respect to their company's reputation and legal repercussion, though they are part of the supply chains.

In my final point, I argue that most suppliers comprising small and medium-sized estates, growers and smallholders are not members of the sustainability standards especially the RSPO. As such, they are not exposed and required to comply with any kind of human rights compliance. The objectives of certification standards such as the RSPO, amongst others, to address the wicked 
environmental and social issues including human rights violations committed by businesses.

Nevertheless, it is important to highlight that while sustainability certification standards are getting more support from industry players mainly among large companies - certification alone is not adequate to guarantee the respect to human rights a reality. Besides, the lack of incentives and added costs to subscribe and/or maintain RSPO membership triggered more uncomfortable feeling among its members Varkkey $(2015,157)$.

\section{CONCLUSION}

The release of the UNGP-BHR in 2011 was meant to assist international community comprising the States, businesses and community at large - to reduce or remove gaps in governance resulting from rapid expansion of businesses across the globe. This study found that large palm oil companies such as FGV, Sime Darby and Wilmar have shown modest progress in reducing some gaps in human rights governance by adopting comprehensive policies that cover their respective business operations and their supply chains. Besides, companies have established due diligence governance framework and strategy to continuously prevent, identify and mitigate any corporate-related human rights harms.

However, this commitment is limited to their own business operations and a few of their suppliers. As mentioned previously, suppliers to FGV, Sime Darby and Wilmar form the vast majority of the palm oil industry players. Consequently, very few of the palm oil industry players that have progressed and reached a scale commensurate with human rights challenges facing the industry. This study argues that the lack of regulatory framework, resources, direct market pressure and membership to sustainability standards continue to serve as critical issues in compensating the gaps in human rights governance.

Discussion in this preliminary article provides opportunities for future research, and may serve as a source of hypotheses for further critical and quantitative studies on human rights governance. For example, future research may further investigate the aspect of human rights disclosure among public listed companies to better understand strategy or system the companies have in place to manage their human rights impacts. Quantitative research may also be undertaken to measure and analyse human rights impacts the companies have in its own business operations, and their suppliers. Further critical research can be initiated to understand the readiness and real challenges facing suppliers in the palm oil sector to commit and fully comply with the expected standards of human rights. 


\section{REFERENCES}

Anon. 2017. "FGV Signs MoU with Felda and SUHAKAM." The Stars. March 30, 2017, accessed November 13, 2018. https://www.thestar.com.my/ business/business-news/2017/03/30/fgv-signs-mou-with-felda-and-suhakam/.

Azman, Ismail. 2013. "The Effect of Labour Shortage in the Supply and Demand of Palm Oil in Malaysia." Oil Palm Industry Economic Journal 13(2): $15-26$.

Chow, E. and A. Ananthalakshmi. 2016. "Palm Oil Industry Watchdog Lax on Human Rights: Critics." Reuters. November 30, 2016, accessed October 3, 2018. https://www.reuters.com/article/us-palmoil-sustainable-rspo/palmoil-industry-watchdog-lax-on-human-rights-critics-idUSKBN13P072.

Creswell, J. W. 2009. Research Design: Qualitative, Quantitative and Mixed Methods Approaches. Thousand Oaks: SAGE Publications.

Felda Global Ventures (FGV). 2016. Sustainability Report 2016-2017. Accessed

November 12, 2018. http://www.feldaglobal.com/wp-content/uploads/2018/06/ FGV-Sustainability-Report-2016_2017.pdf.

FGV. 2018a. FGV's Group Sustainability Policy. Accessed November 19, 2018. http://www.feldaglobal.com/tag/sustainability-policy/.

2018b. FGV Regular Sustainability Update - FGV Enhances Sustainability Commitment. Accessed November 20, 2018. http://www.fgvholdings.com/ fgv-enhances-the-group-sustainability-policy/.

2018c. Update on the Progress of Social and Human Rights (SCHR) Initiatives Undertaken related to WSJ Allegations. April 4, 2018, accessed October 13, 2018. http://www.fgvholdings.com/wp-content/uploads/2018/04/ Letter-to-customer-4th-April-2018-on-WSJ-Action-Plan-update.pdf.

Finnwatch. 2014. The Law of the Jungle: Corporate Responsibility of Finnish Palm Oil Purchases. Accessed October 12, 2018. https://www.finnwatch.org/ images/palmoil.pdf.

Human Rights Commission of Malaysia (SUHAKAM). 2015. Strategic Framework on A National Action Plan on Business and Human Rights for Malaysia. Accessed January 12, 2018. https://www.suhakam.org.my/strategic-frame work-on-a-national-action-plan-on-business-and-human-rights-for-malays ia-2015/.

King, Gary, Robert. O. Keohane, and Sidney Verba. 1994. Designing Social Inquiry:

Scientific Inference in Qualitative Research. New Jersey: Princeton University Press.

Lee, S. 2018. "Estate Operator Allows Workers to Keep Their Passports." The Star. March 17, 2018, accessed November 12, 2018. https://www.thestar.com. my/metro/metro-news/2018/03/17/respecting-labour-rights-estate-operator -allows-workers-to-keep-their-passports/. 
Human Rights Resource Centre. 2013. "Business and Human Rights in ASEAN: A Baseline Study (Malaysia)." Accessed October 23, 2018. http://hrrca.org/ wp-content/uploads/2015/09/Business-and-Human-Rights-in-ASEAN-Bas eline-Study-ebook.pdf.

Malaysian Employers Federation. 2014. "Practical Guidelines for Employers on the Recruitment, Placement, Employment and Repatriation of Foreign Workers in Malaysia." Accessed January 12, 2018. http://www.mef.org. my/Attachments/MEFReport_PGERPERFWM.pdf.

McCorcuodale, Robert, Lise Smit, Stuart Neely and Robin Brooks. 2017. "Human Rights Due Diligence in Law and Practice: Good Practices and Challenges for Business Enterprises." Business and Human Rights Journal 2(2):195-224.

Mohd Nasir, N. E., N. Abdul Halim, N.R. Mohd Sallem, N.S. Jasni and N.F. Aziz. 2013. "Corporate Social Responsibility: An Overview from Malaysia." Journal of Applied Environmental and Biological Sciences 4(10S):82-87.

Nordin, R., M.K. Ishak, R. Shapie, A. Bidin, and M. A. Witbroadt. 2016. "Integrating Human Rights into Business: Current Initiatives in Malaysia." The Law Review (2016): 99-115.

Ruggie, J. G. 2008. "Protect, Respect and Remedy: A Framework for Business and Human Rights." Innovations Technology Governance Globalization 3(2):189-212.

Sime Darby. 2016. Sustainability Report. Sime Darby Plantation. Accessed November 23, 2018.http://www.simedarbyplantation.com/sites/default/files/sustainability/ SimeDarby \%20Plantation_SR2017_dec2016.pdf.

Sime Darby. 2017. Sime Darby Modern Slavery and Human Trafficking Statement. Accessed December 12, 2018. http://www.simedarby.com/ sites/default/files/pdf/sdiar_2017_modern_slavery.pdf.

2018a. Human Rights Charter. Accessed December 12, 2018. http://www. simedarbyplantation.com/sustainability/human-rights-charter.

2018b. Operating Responsibly - Human Rights. Accessed December 12, 2018. http://www.simedarby.com/operating-responsibly/human-rights.

Szulczyk, K. R. 2013. "The Economics of the Malaysian Palm Oil Industry and Its Biodiesel Potential.” SSRN Electronic Version (2013):1-18.

Thanh, Nguyen. C. and Tran Thi Le Thanh. 2015. "The Interconnection between Interpretivist Paradigm and Qualitative Methods in Education." American Journal of Educational Science 1(1):24-27.

The Forest Trust. 2017. TFT-FGV Business Engagement: Support for Transformation - Social Issues. Accessed November 18, 2018. http://www.feldaglobal.com/ wp-content/uploads/2017/05/TFT-Report-Support-for-Transformation.pdf.

Thompson, P. and Zarina Zakaria. 2004. "Corporate Social Responsibility Reporting in Malaysia." Journal of Corporate Citizenship 13(Spring):125-136. 
U.S. Department of State. 2016. "Trafficking in Persons (TIP) Report - Malaysia." June 2016. https://www.state.gov/j/tip/rls/tiprpt/.

United Nations' Human Rights Council (UNHRC). 2011. “United Nations Guiding Principles on Business and Human Rights: Implementing the United Nations Protect, Respect and Remedy Framework." New York: United Nations. Accessed November 21, 2018. https://www.ohchr.org/documents/ publications/GuidingprinciplesBusinesshr_eN.pdf.

Varkkey, H. 2015. "The Human Rights Dimension in the Revised RSPO Principles and Criteria." Malaysian Journal of International Relations 3:153-158.

Wall Street Journal. 2015. "Palm Oil Migrant Workers Tell of Abuses on Malaysian Plantations." Wall Street Journal. July 26, 2015. Accessed November 19, 2018. https://www.wsj.com/articles/palm-oil-migrant-workerstell-of-abuses-on-malaysian-plantations-1437933321.

Wilmar. 2013. "Wilmar International's No Deforestation, No Peat and No Exploitation (NDPE) Policy." Singapore: Wilmar International. Accessed September 21, 2018. http://www.wilmar-international.com/wp-content/uploads/ 2012/11/No-Deforestation-No-Peat-No-Exploitation-Policy.pdf.

Wilmar and Verite. 2017. "Wilmar and Verite Confront Systematic Labour Issues in Indonesia Palm Oil Industry." Singapore: Wilmar International. Accessed November 3, 2018. https://www.google.com/url?sa=t\&source= web\&rct=j\&url=http://www.wilmar-international.com/sustainability/wp-c ontent/uploads/2017/04/Joint-Statement-Wilmar-Verite-Collaboration_Fin al.pdf.

2017. "Sustainability Report." Singapore: Wilmar International. Accessed November 3, 2018. http://www.wilmar-international.com/sustainability/ resource-library/.

2018a. "Sustainability Policies." Singapore: Wilmar International. Accessed November 12, 2018. https://www.wilmar-international.com/sttrsustainability/ policies.

2018b. "About Aggregator Refinery Transformation (ART) Approach." Singapore: Wilmar International. Accessed November 13, 2018. http:// www.wilmar-international.com/sustainability/progress/aggregator-refinery -transformation-art/.

2018c. "Supplier Group Compliance Verification." Singapore: Wilmar International. Accessed November 30, 2018. http://www.wilmar-international. com/sustainability/progress/supplier-group-compliance-verification/.

Yusof, A. 2017. "Nestle Opens Its Global Procurement Hub in Malaysia." New Strait Times. November 23, 2017, accessed September 21, 2018. https:// www.nst.com.my/business/

2017/11/306520/nestle-opens-its-global-procurement-hub-malaysia\%C2\%A0. 